\title{
Development of Korean Disaster Mental Health Support Guidelines: Results of a Scoping Review and a Delphi Survey
}

\author{
Sang Min Lee', Hee Young Lee², Mi Kyung Lee', Sunju Kim¹, Sorae Lee ${ }^{3}$, \\ Hae-Woo Lee ${ }^{4}$, Eun Jin Park ${ }^{5}$, Minyoung Sim ${ }^{6}$, and Jong-Woo Paik ${ }^{1}$ \\ ${ }^{1}$ Department of Psychiatry, School of Medicine, Kyung Hee University, Seoul, Republic of Korea \\ ${ }^{2}$ Center for Preventive Medicine and Public Health, Seoul National University Bundang Hospital, Seongnam, Republic of Korea \\ ${ }^{3}$ Department of Behavioral Health, Brian Allgood Army Hospital/121st Combat Support Hospital, Seoul, Republic of Korea \\ ${ }^{4}$ Department of Psychiatry, Seoul Medical Center, Seoul, Republic of Korea \\ ${ }^{5}$ Department of Psychiatry, Inje University College of Medicine, Ilsan Paik Hospital, Goyang, Republic of Korea \\ ${ }^{6}$ National Center for Trauma, National Center for Mental Health, Seoul, Republic of Korea
}

Objective It is necessary to develop new guidelines to delineate the best ways of providing psychosocial care to ensure mental health following a disaster.

Methods This study applied the scoping review method as a means of establishing evidence-based guidelines for disaster mental health services. A total of 440 literatures were selected through a scoping review of 20,864 documents. Twenty-three recognized experts were invited to participate in the survey and a two-round online Delphi survey was conducted.

Results The concordance rate in the Delphi Round 1 was $95.1 \%$. Six items were excluded and new items were formulated with experts' suggestions. A total of 23 statements were slightly modified to clarify their meaning. In the Delphi Round 2, all items were met with consensus. The three items with the highest consensus among the experts were related to the protection of personal information and privacy. The item with the lowest consensus among experts was related to debriefing. Other items were related to establishing mental health support centers and suicide prevention activities.

Conclusion 140 items were developed through scoping reviews based on evidence-based methodology. These items were used to describe the disaster mental health support identified in Delphi. The guideline will provide a foundation for effective preparation and response in disaster situations.

Psychiatry Investig 2019;16(2):130-138

Key Words Disasters, Mental health, Scoping review, Delphi process.

\section{INTRODUCTION}

Disasters occur on an ongoing basis, resulting in sudden environmental changes and putting people in the position of witnessing family deaths and injuries, leading to stress, anxiety, and fear, which in turn lead to physical and mental health problems. ${ }^{1}$ Most disasters, including both natural and artificial disasters, require policies that address physical and mental health consequences and mitigate the health impacts of

\footnotetext{
Received: September 17, 2018 Revised: November 10, 2018

Accepted: November 14, 2018

$\square$ Correspondence: Jong-Woo Paik, MD, PhD

Department of Psychiatry, School of Medicine, Kyung Hee University, 23

Kyungheedae-ro, Dongdaemun-gu, Seoul 02453, Republic of Korea

Tel: +82-2-958-8419, Fax: +82-2-957-1997, E-mail: paikjw@khu.ac.kr

(ac) This is an Open Access article distributed under the terms of the Creative Commons Attribution Non-Commercial License (https://creativecommons.org/licenses/bync/4.0) which permits unrestricted non-commercial use, distribution, and reproduction in any medium, provided the original work is properly cited.
}

future disasters. ${ }^{2}$

Korea is less affected by natural disasters, such as earthquakes and typhoons, than its neighboring East Asian countries. However, it is vulnerable to the social impact of human casualties and man-made disasters. For example, the Sewol ferry disaster, which occurred on April 16, 2014, involved a tragic incident in which 304 out of 476 passengers on the ferry drowned. ${ }^{3}$ This disaster came as a tremendous shock to the whole country, and the trauma center that was built in Ansan city following the disaster has provided counseling and monitoring for the bereaved families and other people involved. ${ }^{4}$ This has led to an increase in public awareness of the mental and physical consequences of major disasters and has highlighted the need for an effective community response. ${ }^{5,6}$

It has been widely recognized that integrating mental health into medical and emergency situations during disasters is important. Most of the published documents are classified into 
categories of preparedness, response, and recovery, which together provide a theoretical framework for disaster planning. But this categorization is less useful in the delivery of mental health services to individuals.?

Guidelines for providing mental health interventions to individuals to meet their needs in the wake of a disaster are important. It is necessary, therefore, to develop guidelines that delineate the best ways to provide psychosocial care by using limited research evidence available, together with expert opinions, in meaningful ways. ${ }^{8}$ Japan and the European Network for Traumatic Stress (TENTS) published international guidelines on disaster mental health using the Delphi survey method. ${ }^{8,9}$ These guidelines provide a crucial, step-by-step guide to key components of psychosocial support that should be provided in the event of a disaster.

The authors developed new guidelines incorporating the principles of disaster mental health using the scoping review method. The Delphi process was used to gather the responses of Korean experts who have experience in practicing, teaching, consulting, and researching in the field of disaster mental health. In this paper, the authors describe the Delphi process used to revise the guidelines and explain the differences between their results and those of previous studies.

\section{METHODS}

\section{Item development}

In the field of disaster studies, it is difficult to conduct randomized control studies; thus, this research has applied the scoping review method as a way to establish evidence-based guidelines for disaster mental health services. A scoping review is used to identify the extent and nature of research activities on a particular topic. It consists of a procedure that is followed to determine the type and scope of the guidelines, and to review the overall contents in order to identify the more specific contents of domestic and foreign countries in accordance with international research trends. The search was conducted in PubMed and Disaster Lit, and the research strategy was drawn from the EUTENTS group's. Korean databases used in this study include the Korean Studies Information Service System (KISS), the Research Information Sharing Service (RISS), and the DBpia. Hand-searching for grey literature was conducted on the documents published on various research institutes' websites. All published documents written in English and Korean from January 2000 to December 2016 were reviewed; they included narrative reviews, but excluded letters, editorials, and comments. The key question in the scoping review was mental health intervention in disasters. The types of interventions used in this search were as follows: bereavement; cognitive behavioral therapy; debriefing; greif; psychological first aid; psychosocial support to disaster victims; psychosocial support to all disaster response personnel; and PTSD therapy and training.

A total of 440 literatures were selected through a scoping review of 20,864 documents. The overall process of the scoping review is presented in Figure 1. This study is based on the content derived from the scoping review process. The period following a disaster was divided into the following categories:

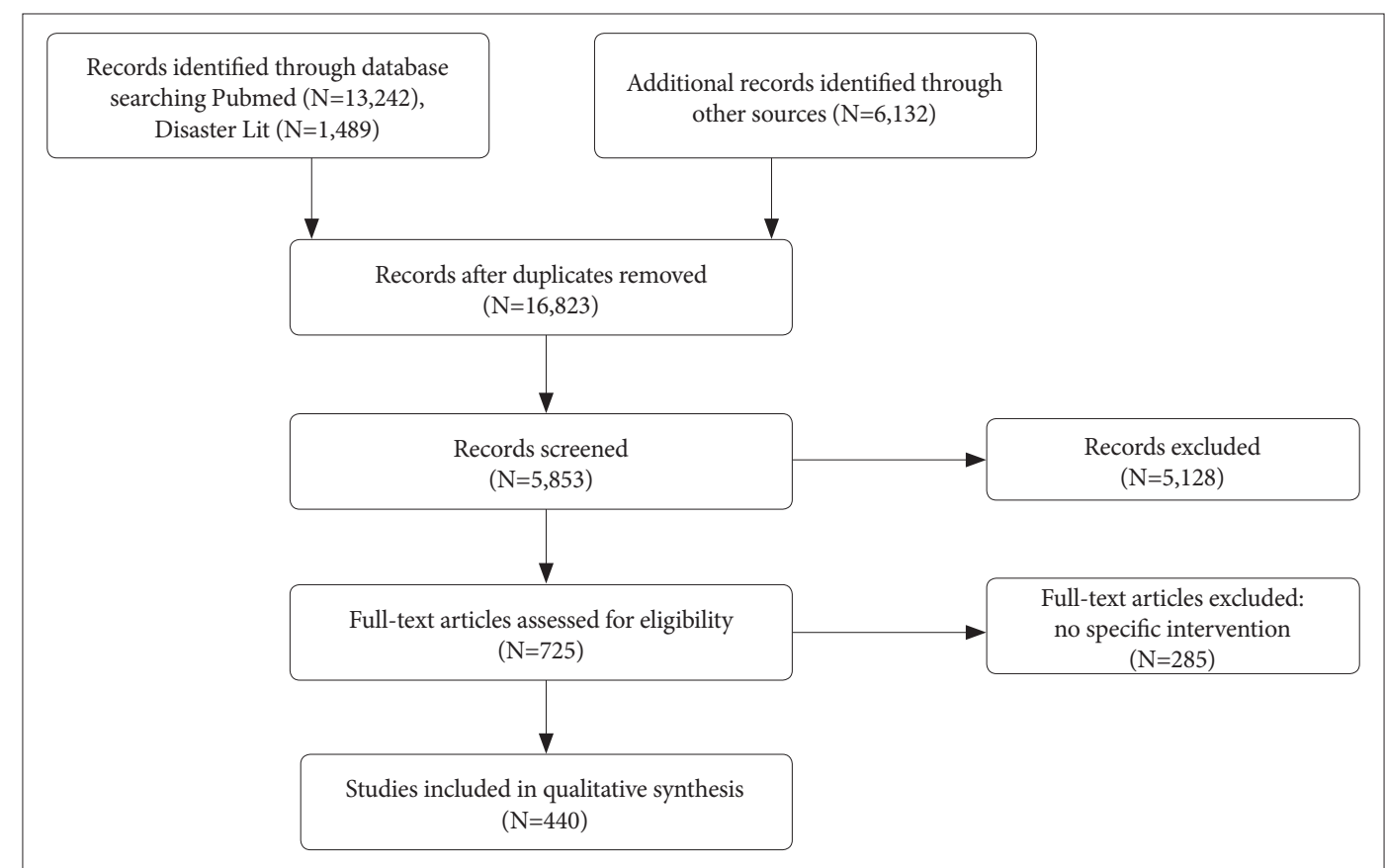

Figure 1. Flow chart of the process of selecting article for scoping review. 
preparatory (before a disaster, comprised of 18 items), acute response (immediately after disaster occurrence, within approximately one week, comprised of 31 items), early response (from one week to one month after a disaster, comprised of 32 items), middle response (one to three months after the disaster, comprised of 25 items), and long-term response (more than three months after the disaster, comprised of 27 items). By dividing the framework of necessary psychological support services into these categories, the author attempted to reduce the disparity between disaster mental health services and to ensure the consistency and continuity of the services provided. This research also included the activities needed during the preparation period before the occurrence of a disaster.

A complete list of the statements will be provided by the author upon request. The online survey was used to present the statements, and provided clear instructions that asked participants to indicate their level of agreement or disagreement using a nine-point scale (1-9), where five was neutral. Participants were also asked to comment on the scores for each statement.

\section{Delphi process}

The Delphi process is a systematic, interactive, structured communication technique used primarily in the medical field for topics around which scientific evidence is lacking. ${ }^{10} \mathrm{~A}$ carefully selected group of experts answer surveys in two or more rounds. The facilitator summarizes the views and comments of the experts anonymously to allow all participants to compare the responses of others with their own. Through this interactive process, the aim is to reduce the scope of the response such that the group converges on the "correct" answer. ${ }^{11}$

A two-round online Delphi survey was conducted from August 2016 to September 2016. Figure 2 summarizes the way in which the items asked during the first round flowed into those that were asked during the second round of the Delphi process. In Round 1, our research team provided the participants with an anonymous summary of the items developed from the scoping review. Of the total 142 items, 25 questions asked participants to rate the appropriateness of each item on a Likert scale (1: not at all appropriate, 9: very appropriate) and the remaining 117 items were checked for disagreement or consensus among the experts. This process was repeated two times to allow all participants to compare and discuss other ratings.

In Round 2, six items that were not agreed upon by experts were deleted. Four items were added according to recommendations from the experts, including research ethics related to disaster health. Some statements were amended slightly to improve clarity as a result of comments from the first round. Participants were then provided with summary results indicating the mean and median score for each item. When applicable, the expert comments were inserted beneath each item for participants to consider when completing the second round.

\section{Analysis}

Descriptive analysis on aspects such as the proportion of participants for each item rating and the mean score of the

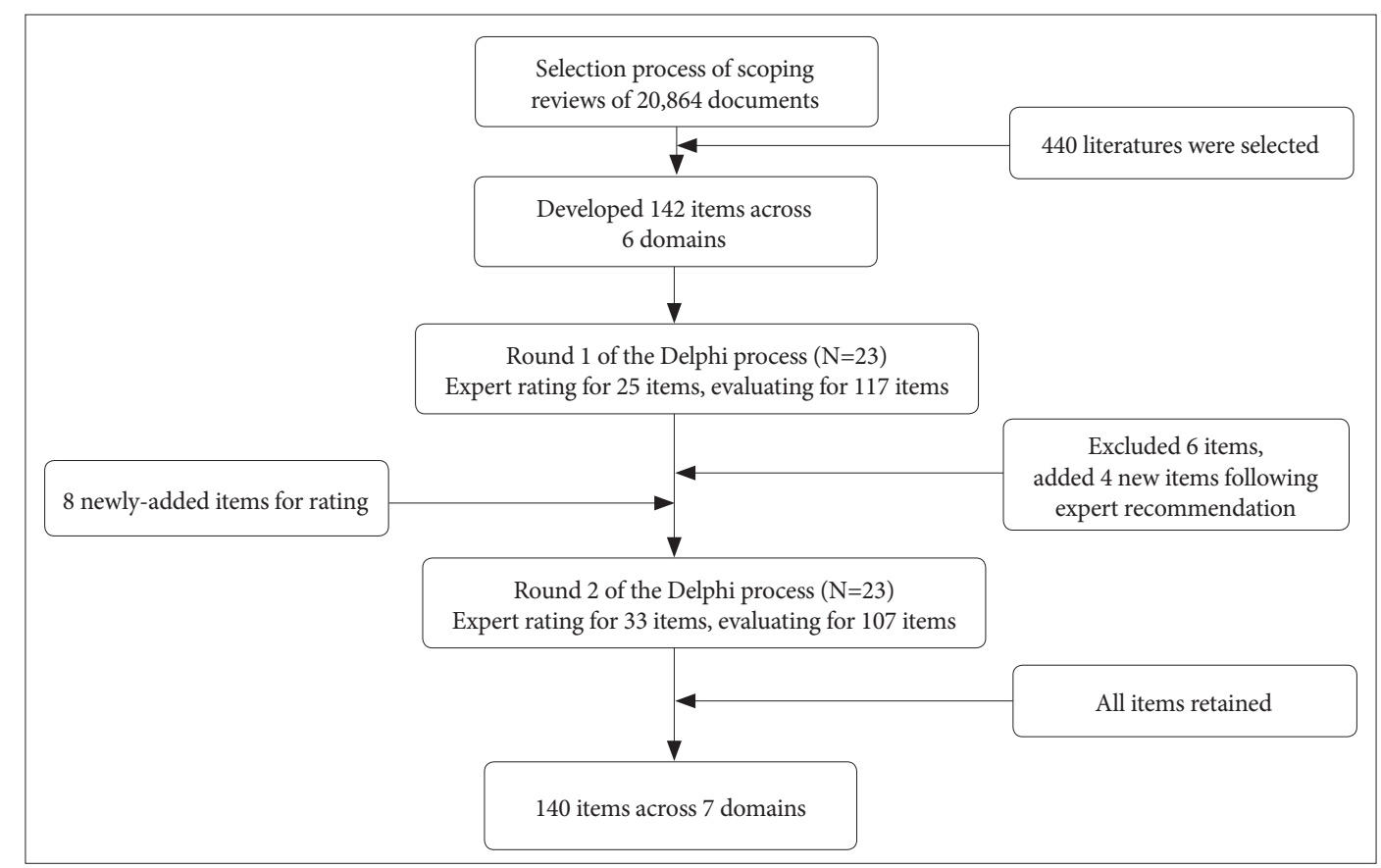

Figure 2. Flow chart of the Delphi process. 
item rating were performed using Microsoft Excel 2017. The Statistical Package for the Social Sciences (SPSS) version 25 (IBM Corp. Released 2017. IBM SPSS Statistics for Windows, Version 25.0. Armonk, NY, USA) was used to determine which statements achieved positive consensus.

\section{Guidelines development}

Following the completion of the two Delphi rounds, the authors drafted guidelines based on the statements that achieved positive consensus. To determine the final wording of the guidelines, consultation with the Psychological Crisis Support Team of the National Mental Health Center was carried out. The final guidelines are provided in Korean and English versions have been made publicly available.

\section{Ethical consideration}

This study protocol was reviewed and approved by the Ethics Committee of Kyung Hee University Hospital (KMC IRB 1520-09). Before beginning the survey, written informed consent from each participant was obtained by either letter or email.

\section{RESULTS}

\section{Characteristics of participants}

Twenty-three recognized experts were invited to participate in the survey and all agreed to participate. The response rates

Table 1. Characteristics of participants in Delphi Participants

\begin{tabular}{lc}
\hline \multirow{2}{*}{ Variable } & Round $1 \& 2(\mathrm{~N}=23)$ \\
\cline { 2 - 2 } Gender & $\mathrm{N}(\%)$ \\
Male & $13(56.5)$ \\
Female & $10(43.5)$ \\
Professional affiliation & \\
Psychiatry & $11(47.8)$ \\
Psychology & $4(17.4)$ \\
Nursing & $4(17.4)$ \\
Psychiatric social work & $4(17.4)$ \\
Activity area & \\
Academia & $15(65.2)$ \\
National and public hospital & $3(13.0)$ \\
Private organization & $3(13.0)$ \\
Other & $2(8.8)$ \\
Direct experience engaged in the disaster site & \\
None & $4(17.4)$ \\
1-2 times & $9(39.1)$ \\
More than 3 times & $10(43.5)$ \\
\hline &
\end{tabular}

were $100 \%$ for both rounds. Psychiatrists accounted for nearly half the participants $(\mathrm{n}=11,47.8 \%)$, followed by psychologists $(n=4,17.8 \%)$, nurses $(n=4,17.8 \%)$, and psychiatric social workers $(n=4,17.8 \%)$. The majority were engaged in academia $(n=15,65.2 \%)$, and many had experience being directly engaged in the disaster site $(n=19,82.6 \%)$. For participant characteristics, please see Table 1.

\section{Round 1}

Based on a previous study, ${ }^{8,9}$ positive consensus was defined as the mean score of the items assessed by the 1-9 point Likert scale, which was $\geq 7$, and the proportion of participants scoring $\geq 7$ was $\geq 70 \%$. Of the original 142 statements, 135 (95.1\%) achieved good consensus in round 1 . Of the 23 items that were rated on the Likert scale, all were met with agreement except for one item related to debriefing. The debriefing-related item had a mean score of 6.57 and the proportion of participants scoring $\geq 7$ was $\geq 65.2 \%$. However, one participant provided a comment which indicated that the questionnaire text should be revised, so the authors decided to include an amended version in Round 2. Six items (5.04\%) were excluded out of the 119 items that were checked for either disagreement or consensus among the experts. As a result of the experts' comments, 23 (16.2\%) statements were slightly modified to clarify their meaning. Four new items were formulated using experts' suggestions.

\section{Round 2}

As in Round 1, the positive consensus criterion was applied. Consensus was reached regarding all 140 statements in Round 2. The results of the analysis showed that all 25 items that were provided in Rounds 1 and 2 met the above criteria (Table 2 ). The item related to debriefing also showed a mean score of 7 and the proportion of participants who scored $\geq 7$ was $\geq 78.3 \%$ in the second survey after the following changes were made to the text: "Collective debriefing is controversial and is thus not to be performed." Figure 3 shows the mean scores and rate (\%) of scores of 7 or above for the eight additional items investigated only in Round 2. All four of the new statements achieved positive consensus.

The three statements with which participants agreed the most strongly were: 1) "Sharing of personal information acquired at the site of disaster mental health support activities should be limited to volunteers (disaster mental health support volunteers) in the area on a need-basis, and strict management of mailing lists, bulletin boards, etc., which can be read by persons other than volunteers, is required." 2) "Disaster mental health support personnel must not disclose any information about the disaster victim that was acquired during the work in any shape or form. This includes, but is not 
Table 2. Main Results of Delphi Rounds for Disaster Mental Health Guidelines

\begin{tabular}{|c|c|c|c|c|c|c|}
\hline \multirow{2}{*}{ Item } & \multicolumn{3}{|c|}{ Round 1} & \multicolumn{3}{|c|}{ Round 2} \\
\hline & M & Mdn & $\geq 7(\%)$ & M & Mdn & $\geq 7(\%)$ \\
\hline \multicolumn{7}{|l|}{ Pre-disaster preparations } \\
\hline $\begin{array}{l}\text { 0.18. It is recommended that professionals receive ongoing education on cooperating } \\
\text { with rescue workers and volunteers, coping with various situations that may arise in } \\
\text { the field, and providing professional services. }\end{array}$ & 7.83 & 8 & 91.3 & 8.04 & 8 & 100 \\
\hline \multicolumn{7}{|l|}{ Early response after disaster (within 1 week of occurrence) } \\
\hline $\begin{array}{l}\text { 1.3. Mental health support immediately following the disaster should be implemented } \\
\text { together with civil volunteers based on establishment of a cooperation structure, but } \\
\text { must be under the charge of an expert or volunteer who at least completed PFA and } \\
\text { understands the basic concepts of disaster mental health support. }\end{array}$ & 8.17 & 8 & 95.7 & 8.35 & 8 & 100 \\
\hline $\begin{array}{l}\text { 1.4. Simple item-specific questionnaires may be used to identify current difficulties } \\
\text { such as physical difficulties, psychological difficulties, and urgent needs. }\end{array}$ & 7.74 & 8 & 87.0 & 7.83 & 8 & 95.7 \\
\hline $\begin{array}{l}\text { 1.8. The service program is to apply established evidence and avoid unfounded } \\
\text { methods of interpretation. }\end{array}$ & 8.22 & 9 & 91.3 & 8.35 & 8 & 100 \\
\hline 1.9. Collective debriefing is controversial and thus not to be performed. & 6.57 & 7 & 65.2 & 7 & 7 & 78.3 \\
\hline $\begin{array}{l}\text { 1.10. Disaster mental health support personnel must not disclose any information } \\
\text { about the disaster victim that was acquired during the work in any shape or form. } \\
\text { This includes, but is not limited to the types of medium such as interviews with } \\
\text { media, personal websites, and social network sites (SNS). }\end{array}$ & 8.65 & 9 & 100 & 8.70 & 9 & 100 \\
\hline $\begin{array}{l}\text { 1.11. Suicide prevention activities are to be conducted in parallel, and early intervention } \\
\text { of suicide prevention such as police investigation is to be carried out in the event of } \\
\text { crisis situations. Particular attention must be paid to the risk of suicide for person(s) } \\
\text { responsible for the disaster and other related person(s), and professional evaluation is } \\
\text { to be performed if necessary. The statement assistant system in police and prosecution } \\
\text { investigations for person(s) responsible for or related to the disaster may be utilized as } \\
\text { a part of this activity. }\end{array}$ & 7.52 & 8 & 82.6 & 7.65 & 8 & 95.7 \\
\hline $\begin{array}{l}\text { 1.28. Ensure there are no situations that can aggravate the mental suffering of disaster } \\
\text { victims such as stigmatization of people, dispersion of prejudiced/hate messages, } \\
\text { or aggressive questioning of their emotional experiences through inappropriate } \\
\text { interviewing methods, and announce the coverage guidelines to ensure they are } \\
\text { observed. }\end{array}$ & 8.43 & 9 & 100 & 8.61 & 9 & 100 \\
\hline $\begin{array}{l}\text { 1.29. It is advised that journalists go through the emergency headquarters when } \\
\text { meeting with disaster victims. }\end{array}$ & 8.13 & 8 & 95.7 & 8.26 & 9 & 95.7 \\
\hline \multicolumn{7}{|l|}{ Early response after disaster (within 1 week -1 month) } \\
\hline $\begin{array}{l}\text { 2.3. The use of external resources must strictly be under the control of the local } \\
\text { headquarters. }\end{array}$ & 8.04 & 8 & 95.7 & 8.17 & 8 & 95.7 \\
\hline $\begin{array}{l}\text { 2.4. If an external volunteer wants to have contact with a disaster victim, he or she must } \\
\text { register with the emergency headquarters and have a reporting system in place. }\end{array}$ & 8.26 & 8 & 95.7 & 8.43 & 8 & 95.7 \\
\hline $\begin{array}{l}\text { 2.11. Implement early detection and early intervention by conducting preventive } \\
\text { education and screening. }\end{array}$ & 8.30 & 8 & 100 & 8.26 & 8 & 100 \\
\hline $\begin{array}{l}\text { 2.12. Professionals may use checklists in a useful way, but must apply them } \\
\text { appropriately, considering the circumstances. }\end{array}$ & 8.17 & 8 & 100 & 8.17 & 8 & 100 \\
\hline $\begin{array}{l}\text { 2.15. PFA should be implemented for disaster victims. PFA administrators should } \\
\text { describe the symptoms experienced by victims as normal reactions as much as } \\
\text { possible, but elevate the patient to professional care if there are symptoms such as } \\
\text { insomnia, panic, emotion regulation disorder, delusions, etc. }\end{array}$ & 8.30 & 8 & 100 & 8.43 & 8 & 100 \\
\hline $\begin{array}{l}\text { 2.22. The emergency response headquarters should manage evaluation and counseling } \\
\text { records under their responsibility, and take a belts-and-braces approach to transition } \\
\text { and protection of personal information. }\end{array}$ & 8.57 & 9 & 100 & 8.70 & 9 & 100 \\
\hline
\end{tabular}


Table 2. Main Results of Delphi Rounds for Disaster Mental Health Guidelines (continued)

\begin{tabular}{|c|c|c|c|c|c|c|}
\hline \multirow{2}{*}{ Item } & \multicolumn{3}{|c|}{ Round 1} & \multicolumn{3}{|c|}{ Round 2} \\
\hline & M & Mdn & $\geq 7(\%)$ & M & Mdn & $\geq 7(\%)$ \\
\hline \multicolumn{7}{|l|}{ Response after 3 months following a disaster } \\
\hline $\begin{array}{l}\text { 4.1. Disaster mental health support and case management should be provided for a few } \\
\text { years after the incidence of disasters. }\end{array}$ & 7.95 & 8 & 91.3 & 7.91 & 8 & 95.7 \\
\hline 4.23. Provide education to the family or guardian of those suffering from a disaster. & 8.32 & 8 & 100 & 8.43 & 8 & 100 \\
\hline \multicolumn{7}{|l|}{ Providing and exporting information } \\
\hline $\begin{array}{l}\text { 5.1. Sharing of personal information acquired at the site of disaster mental health } \\
\text { support activities should be limited to volunteers (disaster mental health support } \\
\text { volunteers) in the area on a need-basis, and strict management of mailing lists, } \\
\text { bulletin boards, etc. which can be read by persons other than volunteers is required. }\end{array}$ & 8.65 & 9 & 100 & 8.83 & 9 & 100 \\
\hline \multicolumn{7}{|l|}{ Support for volunteers } \\
\hline 6.1. Prevent excessive workloads and ensure rest. & 8.35 & 9 & 100 & 8.57 & 9 & 100 \\
\hline $\begin{array}{l}\text { 6.2. Prepare for disaster by creating manuals or conducting training so that the entire } \\
\text { organization can understand the staff working system, especially the need to rest, in } \\
\text { the event of a disaster. }\end{array}$ & 8.30 & 8 & 100 & 8.39 & 8 & 100 \\
\hline 6.3. Schedule shift work so that volunteers can take breaks when disaster strikes. & 8.17 & 8 & 100 & 8.30 & 8 & 100 \\
\hline $\begin{array}{l}\text { 6.4. When responding to a disaster, a separate resting place should be set up to secure } \\
\text { privacy at work and in the shelter, even if the volunteer is unable to rest sufficiently. }\end{array}$ & 8.08 & 9 & 95.7 & 8.30 & 8 & 100 \\
\hline $\begin{array}{l}\text { 6.5. Conduct sufficient education on self-care through workshops, etc. even in non-crisis } \\
\text { situations }\end{array}$ & 8.13 & 8 & 100 & 8.30 & 8 & 100 \\
\hline $\begin{array}{l}\text { 6.6. Conduct screening to identify the stress and mental health conditions of volunteers } \\
\text { caused by disaster response. }\end{array}$ & 7.96 & 8 & 87.0 & 8.00 & 8 & 91.3 \\
\hline $\begin{array}{l}\text { 6.7. Provide training, counseling, and management to strengthen the competence of } \\
\text { support personnel. }\end{array}$ & 8.17 & 8 & 95.7 & 8.30 & 8 & 95.7 \\
\hline
\end{tabular}
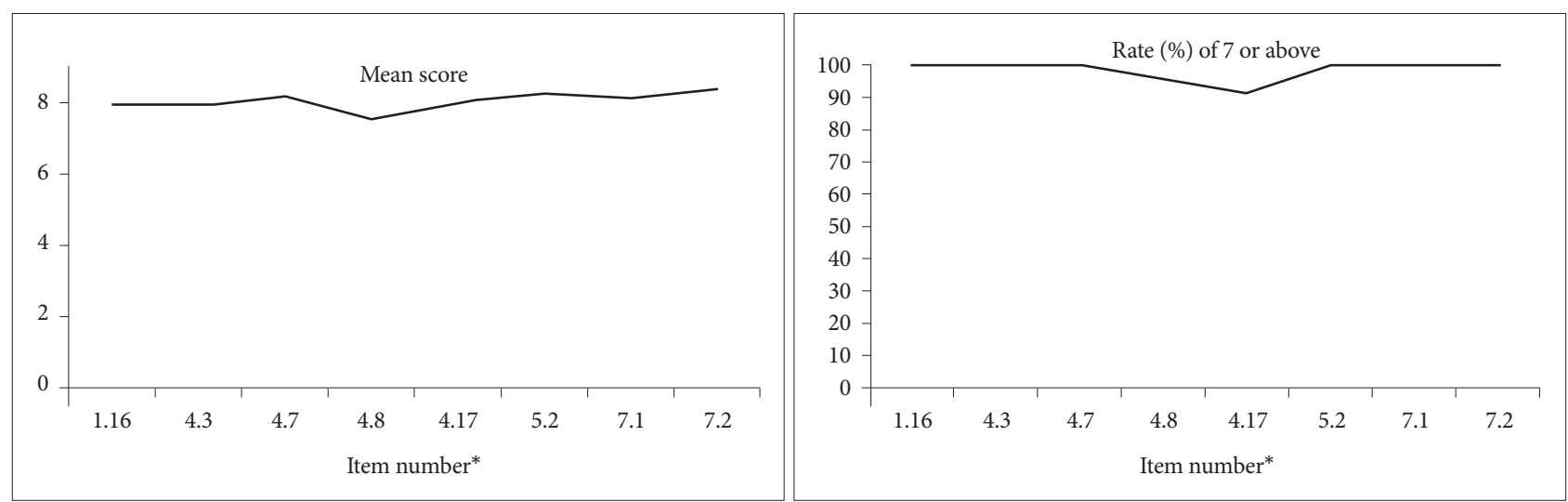

Figure 3. Mean scores and rate (\%) of a score of 7 or above for the 8 additional investigated items in round two. *statements corresponding to each number are given in the Korean Disaster Mental Health Support Guidelines for Mental Health Professional.

limited to the types of medium such as interviews with media, personal websites, and social network sites (SNS)." 3) "The emergency response headquarters should manage evaluation and counseling records under their responsibility, and take a belts-and-braces approach to transition and protection of personal information."

The three statements with which participants disagreed most strongly were: 1) "Collective debriefing is controversial and thus not to be performed." 2) "Establish a center for mental health support based on the scale of the disaster. If there is an on-premise mental health promotion center, it can be considered as priority. If the size of the existing mental health promotion center is inadequate, a separate center can be established." 3) "Suicide prevention activities are to be conducted in parallel, and early intervention of suicide prevention such as police investigation is to be carried out in the event of 
crisis situations. Particular attention must be paid to the risk of suicide for person(s) responsible for the disaster and other related person(s), and professional evaluation is to be performed if necessary. The statement assistant system in police and prosecution investigations for person(s) responsible for or related to the disaster may be utilized as a part of this activity."

\section{DISCUSSION}

The need for mental health services is significant just before and after a disaster. Appropriate responses to disasters should be provided at all phases of mitigation, preparedness planning, response, and recovery. ${ }^{12}$ Disaster management is a continuous and integrated cyclical process intended to ensure the effective prevention and management of disasters ; thus, planning and preparedness efforts are essential in meeting these challenges. ${ }^{13}$ The guidelines were intended to share the framework of mental health support services as well as the common knowledge and practice by experts in each disaster period. Therefore, this guideline was intended to represent the contents revealed by the scoping review method in greater detail than other existing guidelines for each disaster period. This is the most significant difference of this guideline. In the case of a disaster, it is difficult to investigate systematically because it is a unique and urgent situation; as an alternative, the scoping review method was applied. This guideline summarizes the results of reaffirming parts of the guideline that disaster mental health experts in Korea have found controversial.

Compared with previous studies in Europe and Japan, the rate of consensus was high in this Delphi survey. This is because the research team gathered evidence by collecting as much data as possible using the scoping review method, and the draft was created based on the existing TENTS and Japan guidelines. In 2015, a Delphi survey of disaster mental health services was conducted in Japan. ${ }^{14}$ This survey was focused on the services needed in each disaster period. In comparison with Japan, this study has the merit of confirming the necessary interventions for disaster preparedness before the disaster. In 2016, Korean child-adolescent psychiatrists conducted a Delphi survey of the major elements of psychological assessment and intervention for children and adolescents after a disaster. ${ }^{15}$ Compared with Bhang's analysis, ${ }^{15}$ this study included more comprehensive items despite the lack of consideration for special populations such as children and adolescents.

The three items with the highest consensus among the experts were related to the protection of personal information and privacy in this Delphi survey. One reason for this is that the victims and survivors of the Sewol ferry disaster were students who had a great impact on Korean society and criti- cism of the media and the protection of personal privacy were increased due to excessive reporting on the minors who were the victims in this disaster. ${ }^{5,16}$ Another reason is that South Korea does not have many natural disasters ${ }^{17}$ and it is thought that the study of disaster aftermaths reflects a national sentiment that indicates a lack of familiarity with this type of disaster.

Almost all guidelines underscored that the research in disaster settings should be cautious about to be balanced between the need for scientific evidence and the need to protect participants from possible harm sustained from the research itself. $^{18}$ In the Round 1 Delphi process, many experts commented on the importance of research at the disaster site and research ethics applied throughout the process. In this regard, the disaster mental health guidelines also require emphasis on research ethics, and unlike other country guidelines, this section is included in the Korean guidelines.

The item with the lowest consensus among experts in this Delphi survey was one related to debriefing. Psychological debriefing is one of the most commonly described intervention methods in disaster mental health literature. It consists of one or more individual or group sessions for hours or days after a traumatic event. ${ }^{7}$ Although single session debriefing is generally recommended after traumatic events and disasters, meta-analysis studies found limited evidence of its effectiveness. ${ }^{19}$ The long-term follow-up study of this review demonstrated that symptoms of post-traumatic stress in individuals who were debriefed were significantly worse. ${ }^{19}$ However, since this intervention has gained considerable international popularity, it was difficult to reach consensus through the Delphi process, even after modifying the phrase related to group debriefing in this study. Due to the controversial consequences, group debriefing was not adopted in this guideline.

The TENTS guidelines include the recommendation that governments/authorities provide adequate funding to maintain an appropriate psychosocial care plan that can be effectively delivered in the event of a disaster. ${ }^{8}$ In this guideline, a consensus was readily obtained regarding the role of governments and administrations in pre-disaster preparations. The item, which stated that a mental health support center could be established according to the scale of a given disaster during the 1-3 months following the disaster, was met with consensus but at a low rate. If an on-premise mental health promotion center is already established, it is described in the statement to ensure it can be considered as the priority. However, since the mental health promotion center in Korea is currently charged with a heavy workload, it is unreasonable for professionals in the mental health promotion centers to take on disaster-related tasks. ${ }^{20}$ It is necessary to establish acute phase service infrastructures in line with the establishment 
of the National Trauma Center in 2018.

Another item with a low consensus rate was a suicide prevention item. It is known that suicide rates tend to increase in the aftermath of devastating disasters. Since there are few reports of factors related to disasters, it is difficult to discuss the ways in which these events affect suicide rates. ${ }^{21,22}$ There were two suicides after the Sewol ferry disaster; one person was a vice principal and one was the father of a drowned student. In another disaster, the manager committed suicide after the Pangyo vent hole collapse. For this reason, no suiciderelated items were included in other disaster mental health guidelines, and it was observed that the level of agreement on this item was also low in this Delphi survey. Suicide is an even more serious public health problem, especially in South Korea. Instances of suicide have consistently increased since 1985 , and in 2010, the rate of suicide was more than 30 per 100,000 people. $^{23}$ As a result, suicide was the fourth leading cause of death in Korea. ${ }^{24}$ In addition, Korea's age-standardized suicide rate was 31.2 per 100,000 people, the highest among OECD countries (11.3 per 100,000). ${ }^{25}$ In Japan, depression and PTSD, which are risk factors of suicide, increased after the Great East Japan Earthquake. ${ }^{26}$ The suicide mortality rate decreased immediately after the disaster but started to increase in the three years following the disaster. Japan tends to emphasize on disaster-related suicides. Considering the specificity of Korea and the experience of Japan, it is included in the guideline that suicide prevention activities. ${ }^{27}$

The limitations of this study are as follows. The controversy surrounding Delphi method-based studies is related to the number of expert panels. If there are a large number of panels, the difference in expertise among the panels may be a problem, whereas when the number of panels is small, a problem in representation may be present. ${ }^{28}$ There may be criticism related to the number of expert panels in this study. An examination of the number of existing Delphi panels showed that a panel of 15 researchers did not differ in the median of the study results ${ }^{29}$; the panel from this study can be assumed to be a sample from a group of individuals who have expert opinions that are appropriate for the purpose of this study. Another limitation is that the expert panels' participation in the disaster site is less than two times, which accounts for more than half of the total. Although the expert panels have been chosen strictly by the author, their quality and the quantity of the panels' disaster-involved experiences were not strictly controlled. Moreover, it has not been long since Korea began addressing the mental health needs of disaster victims and enlisted the active participation of experts. The last limitation is that some of the proposed items were ambiguous and needed clarification. Delphi Round 1 was completed and the research team corrected some wording for the next round to overcome this limitation.

In conclusion, the research team gathered as much evidence as possible by selecting 440 literatures through a scoping review of 20,864 documents. We have attempted to reinforce the contents of the existing guidelines with more comprehensive content. We have included necessary items in the preparation stage before the disaster and have shared a framework of psychological support services needed after each disaster period to reduce the disparity of disaster mental health support services and ensure the consistency and continuity of services. As such, a Delphi survey was conducted with disaster mental health experts. The concordance rate in the Delphi Round 1 was $95.1 \%$ and the concordance rate in Round 2 was $100 \%$. This guideline reflected the social and cultural differences of South Korea, including the protection of personal information and privacy, research ethics at the disaster site, and intervention for suicide prevention. It is important to develop and apply disaster mental health guidelines that are tailored to each country. In order for the guidelines to be used efficiently, it is necessary to continuously apply the program to the disaster site and to verify its application on an ongoing basis.

\section{Acknowledgments}

This study was supported by a grant of the Korean Mental Health Technology R\&D Project, Ministry of Health \& Welfare, Republic of Korea (HM 15C1112)

\section{REFERENCES}

1. Chung S, Kim E. Physical and mental health of disaster victims: a comparative study on typhoon and oil spill disasters. J Prev Med Public Heal 2010;43:387-395.

2. Thorpe LE, Assari S, Deppen S, Glied S, Lurie N, Mauer MP, et al. The role of epidemiology in disaster response policy development. Ann Epidemiol 2015;25:377-386.

3. Han KM, Kim KH, Lee M, Lee SM, Ko YH, Paik JW. Increase in the prescription rate of antidepressants after the Sewol Ferry disaster in Ansan, South Korea. J Affect Disord 2017;219:31-36.

4. Yang HJ, Cheong HK, Choi BY, Shin MH, Yim HW, Kim DH, et al. Community mental health status six months after the Sewol ferry disaster in Ansan, Korea. Epidemiol Health 2015;37:e2015046.

5. Woo H, Cho Y, Shim E, Lee K, Song G. Public trauma after the Sewol ferry disaster: The role of social media in understanding the public mood. Int J Environ Res Public Health 2015;12:10974-10983.

6. Paik JW, Kim HS, Sim MY, Lee HK, Woo YS, Chung CS, et al. The Sewol ferry accident and early mental health care response by volunteer activities of Korean disaster mental health committee and members of Korean Neuropsychiatric Association. J Korean Neuropsychiatr Assoc 2015;54:1-5.

7. North CS, Pfefferbaum B. Mental health response to community disasters: A systematic review. JAMA 2013;310:507-518.

8. Bisson JI, Tavakoly B, Witteveen AB, Ajdukovic D, Jehel L, Johansen VJ, et al. TENTS guidelines: Development of post-disaster psychosocial care guidelines through a Delphi process. Br J Psychiatry 2010;196: 69-74.

9. Suzuki Y, Fukasawa M, Nakajima S, Narisawa T, Kim Y. Development of disaster mental health guidelines through the Delphi process in Ja- 
pan. Int J Ment Health Syst 2012;6:7.

10. Kelly CM, Jorm AF, Kitchener BA. Development of mental health first aid guidelines on how a member of the public can support a person affected by a traumatic event: a Delphi study. BMC Psychiatry 2010; 10:49.

11. Skulmoski GJ, Hartman FT, Krahn J. The Delphi method for graduate research. J Inf Technol Educ 2007;6:1-21.

12. Roudini J, Khankeh HR, Witruk E. Disaster mental health preparedness in the community: a systematic review study. Heal Psychol Open 2017;4: 2055102917711307.

13. Math SB, Nirmala MC, Moirangthem S, Kumar NC. Disaster management: Mental health perspective. Indian J Psychol Med 2015;37:261-271.

14. Fukasawa M, Suzuki Y, Nakajima S, Asano K, Narisawa T, Kim Y. Systematic consensus building on disaster mental health services after the Great East Japan earthquake by phase. Disaster Med Public Health Prep 2015;9:359-366.

15. Park J, Lee M, Chang HY, Hwang J, Lee J, Kim J, et al. The major elements of psychological assessment and intervention for children and adolescents after a disaster : a professional delphi preliminary survey. J Korean Acad Child Adolesc Psychiatry 2016;27:164-172.

16. Lim YH. A study on the coverage behavior of television news on the Sewol ferry catastrophe. Soc Sci Stud 2014;25:179-201.

17. Ha KM. Disasters can happen to anybody: the case of Korea. Environ Impact Assess Rev 2016;57:1-9.

18. Mezinska S, Kakuk P, Mijaljica G, Waligóra M, O’Mathúna DP. Research in disaster settings: a systematic qualitative review of ethical guidelines. BMC Med Ethics 2016;17:62.

19. Rose S, Bisson J, Churchill R, Wessely S. Psychological debriefing for preventing post traumatic stress disorder (PTSD). Cochrane Database
Syst Rev 2002;(2):CD000560.

20. Roh S, Lee SU, Soh M, Ryu V, Kim H, Jang JW, et al. Mental health services and R\&D in South Korea. Int J Ment Health Syst 2016;10:45.

21. Kõlves K, Kõlves KE, De Leo D. Natural disasters and suicidal behaviours: A systematic literature review. J Affect Disord 2013;146:1-14.

22. Orui M, Harada S, Hayashi M. Changes in suicide rates in disasterstricken areas following the Great East Japan Earthquake and their effect on economic factors: an ecological study. Environ Health Prev Med 2014;19:459-466.

23. Jeon SY, Reither EN, Masters RK. A population-based analysis of increasing rates of suicide mortality in Japan and South Korea, 19852010. BMC Public Health 2016;16:356.

24. Kim Y, Kim H, Kim DS. Association between daily environmental temperature and suicide mortality in Korea (2001-2005). Psychiatry Res 2011;186:390-396.

25. Park S, Choi JW, Kyoung Yi K, Hong JP. Suicide mortality and risk factors in the 12 months after discharge from psychiatric inpatient care in Korea: 1989-2006. Psychiatry Res 2013;208:145-150.

26. Maeda M, Oe M. Mental health consequences and social issues after the Fukushima disaster. Asia-Pacific J Public Health 2017;29(2 Suppl): 36S-46S.

27. Ohto $H$, Maeda $M$, Yabe $H$, Yasumura $S$, Bromet EE. Suicide rates in the aftermath of the 2011 earthquake in Japan. Lancet 2015;385:1727.

28. Avella JR. Delphi panels: Research design, procedures, advantages, and challenges. Int J Dr Stud 2016;11:305-321.

29. Dalkey N, Brown B, Cochran S. Use of self-ratings to improve group estimates. Experimental evaluation of delphi procedures. Technol Forecast 1970;1:283-291. 